\title{
Preparation of Room Temperature Curable Organic-inorganic Hybrid Thermal Control Coatings
}

\author{
LIU Ding ${ }^{1,2,3}$, YU Yang ${ }^{1}$, MI Le ${ }^{1}$, YU Yun ${ }^{1}$, SONG Li-Xin ${ }^{1}$
}

(1. Key Laboratory of Inorganic Coating Materials of CAS, Shanghai Institute of Ceramics, Chinese Academy of Sciences, Shanghai 200050, China; 2. University of Chinese Academy of Sciences, Beijing 100049, China; 3. School of Physical Science and Technology, Shanghai Tech University, Shanghai 201210, China)

\begin{abstract}
A series of organic-inorganic hybrid thermal control coatings (TCCs) were prepared. The binder was prepared by co-pre-hydrolysis/condensation of tetraethylorthosilicate (TEOS) and siloxane, subsequently mixing with 3-aminopropyltriethoxysilane (APTES) as curing catalyst and $\mathrm{ZnO}$ powder as optical pigment. The coatings can be cured at room temperature naturally with low solar absorptance $\alpha_{\mathrm{S}}$ and high thermal emittance $\varepsilon_{\mathrm{H}}$. Fourier transform infrared spectroscopy (FT-IR) and gel permeation chromatography (GPC) measurements were carried out to understand the structures of the coatings. FT-IR spectra and GPC analysis results showed that the as-prepared hybrid binder carried lots of active hydroxyls with an appropriate polymerization degree. Thermal gravimetric analyzer (TGA) test showed that as-prepared coatings have high thermal stability at $200^{\circ} \mathrm{C} . \alpha_{\mathrm{S}} / \varepsilon_{\mathrm{H}}$ value could be further reduced by increasing the coating thickness, and optical absorption of the coatings in the infrared wave band could be further reduced by increasing TEOS content. This work provides an effective way to obtain room temperature cured TCCs with low $\alpha_{\mathrm{S}} / \varepsilon_{\mathrm{H}}$ value.
\end{abstract}

Key words: room temperature curing method; TCCs; thermal stability; low $\alpha_{\mathrm{S}} / \varepsilon_{\mathrm{H}}$ value

Thermal control coatings (TCCs) play a vital role in the thermal management of spacecrafts via reflecting incident solar energy and emitting infrared heat. The temperature control ability of TCCs can be characterized by their solar absorptance $\alpha_{\mathrm{S}}$ and the thermal emittance $\varepsilon_{\mathrm{H}}{ }^{[1]}$. There are many different types of TCCs including uncovered metal surface, optical solar reflector, paint coating, and electrochemistry coating ${ }^{[2]}$. The paint coating is the most convenient for being operated on different surfaces with complicated shapes. Among the paint coatings, the inorganic white TCCs have been widely used on the surface of craft radiator because of their low $\alpha_{\mathrm{S}}$ value and high $\varepsilon_{\mathrm{H}}$ value. Normally, the inorganic white TCCs are composed of white pigment particles $(\mathrm{ZnO}$, $\mathrm{TiO}_{2}, \mathrm{ZrO}_{2}$, etc) and inorganic binder ${ }^{[2-3]}$. The $\mathrm{ZnO}$-silicate based TCCs have exhibited excellent stability in space environment ${ }^{[3-4]}$. However, the curing temperature of them normally exceeds $100^{\circ} \mathrm{C}$, which is very energyintensive and inadequacy for many substrates which are not heat-resisting. A series of room temperature curable organic coatings using methyl silicone or acrylic resin and epoxy resin as binder have also been developed ${ }^{[5-7]}$. However, these organic coatings have inferior spatial sta- bility. In recent years, organic-inorganic hybrid binder has attracted great interest for its excellent performance by integrating organic-inorganic properties ${ }^{[8-13]}$. What's more, most of the hybrid binders can be prepared in a mild synthesis way, and the as-prepared coatings can be room temperature curable or UV-curable ${ }^{[11-13]}$. The ratio of the organic to inorganic components and the polymerization degree of the organic components are significant to the properties of the final products ${ }^{[14]}$.

In this paper, a novel room temperature cured binder has been successfully synthesized by organic-inorganic hybrid process, and the $\mathrm{ZnO}$-based TCCs using the assynthesized hybrid binder have also been obtained, which show good mechanical and thermal optical properties.

\section{Experiments}

\subsection{Materials}

Tetraethylorthosilicate (TEOS, 98\%), dimethyldimethoxysilane (DMDS, 98\%), methyltriethoxysilane (MTES, 98\%) and 3-aminopropyltriethoxysilane (APTES, 98\%) were purchased from Aladdin reagent Co, Ltd. (China). The absolute ethanol (EtOH, AR), acetone $\left(\mathrm{C}_{3} \mathrm{H}_{6} \mathrm{O}, \mathrm{AR}\right)$, 
sodium hydroxide $(\mathrm{NaOH}, \mathrm{AR})$, zincoxide ( $\mathrm{ZnO}, \mathrm{AR})$ and hydrochloric acid ( $\mathrm{HCl}, \mathrm{AR})$ were purchased from Sinopharm Chemical Reagent Co, Ltd. (China). All chemicals were used as received. Deionized water was used throughout the experiments.

\subsection{Organic-inorganic hybrid binder}

The organic-inorganic hybrid binder was prepared by co-hydrolysis/condensation of TEOS and siloxane. Firstly, TEOS and siloxane were added into a $100 \mathrm{~mL}$ round-bottom flask, which was equipped with a condenser. The aqueous $\mathrm{HCl}$ with the concentration of $1 \mathrm{~mol} / \mathrm{L}$ dissolved in absolute EtOH solution was added dropwise to the mixture within 10 min stirred by a magnetic stir bar. Then the mixture was heated and refluxed at $80^{\circ} \mathrm{C}$ for $4 \mathrm{~h}$ using water bath to obtain the target product. The dosages of the raw materials are listed in Table 1 . The samples were nominated as "TMDxy-ab", where "T", "M" and "D" correspond to "TEOS", "MTES" and "DMDS" respectively. " $x y$ " denotes to the molar ratio of TEOS to the sum of MTES and DMDS. " $a b$ " denotes to the molar ratio of MTES to DMDS. For example, TMD14-28 means that the molar ratios of the reactants are TEOS/(MTES+DMDM) $=1 / 4$, and MTES/ DMDS $=$ $2 / 8$.

\subsection{Room temperature curing coatings}

After the co-pre-hydrolysis/condensation described in section 1.2 , hydrolysate as well as polysiloxane oligomers were generated. Then a certain amount of APTES, $\mathrm{ZnO}$ powder and $\mathrm{NaOH}$ solution were successively added to the as-prepared hybrid binder. The mixture was
Table 1 The dosages of the raw materials for synthesis of the hybrid binder

\begin{tabular}{cccccc}
\hline Samples & $\begin{array}{c}\text { TEOS } \\
/ \mathrm{mol}\end{array}$ & $\begin{array}{c}\text { MTES } \\
/ \mathrm{mol}\end{array}$ & $\begin{array}{c}\text { DMDS } \\
/ \mathrm{mol}\end{array}$ & $\begin{array}{c}\mathrm{HCl} \\
/ \mathrm{mol}\end{array}$ & $\begin{array}{c}\mathrm{H}_{2} \mathrm{O} \\
/ \mathrm{mL}\end{array}$ \\
\hline TMD14-28 & 0.025 & 0.02 & 0.08 & 0.001 & 1.0 \\
TMD14-55 & 0.025 & 0.05 & 0.05 & 0.001 & 1.0 \\
TMD14-82 & 0.025 & 0.08 & 0.02 & 0.001 & 1.0 \\
TMD12-28 & 0.05 & 0.02 & 0.08 & 0.001 & 1.5 \\
TMD12-55 & 0.05 & 0.05 & 0.05 & 0.001 & 1.5 \\
TMD12-82 & 0.05 & 0.08 & 0.02 & 0.001 & 1.5 \\
TMD11-28 & 0.10 & 0.02 & 0.08 & 0.001 & 2.0 \\
TMD11-55 & 0.10 & 0.05 & 0.05 & 0.001 & 2.0 \\
TMD11-82 & 0.10 & 0.08 & 0.02 & 0.001 & 2.0 \\
\hline
\end{tabular}

grinded for $12 \mathrm{~h}$. Herein, APTES not only participated in the further condensation of the hydrolysate and polysiloxane oligomers, but also acted as a catalyst ${ }^{[15]}$. The dosages of materials are listed in Table 2. The samples were nominated as "BZSI- $X$ - $Y$ ", where " $X$ " corresponds to the mass ratio of $\mathrm{ZnO}$ to the binder, and " $Y$ " denotes to the mass percentage of APTES to the binder. It should be noted that the binder " $\mathrm{B}$ " has different constitutions, as shown in Table 2.

\subsection{TCCs samples}

The ZnO-based TCCs samples were prepared by spraying on aluminum substrate and glass fiber reinforced plastics (GFRP) with pneumatic type airbrush using $\mathrm{N}_{2}$ as carrier gas. The coatings were sprayed layer by layer to a specific thickness and cured at room temperature for $24 \mathrm{~h}$.

Table 2 Dosages of materials used in the white TCCs preparation process

\begin{tabular}{cccccccccc}
\hline Samples & BZSI-1-20 & BZSI-1-30 & BZSI-1-40 & BZSI-1.25-20 & BZSI-1.25-30 & BZSI-1.25-40 BZSI-1.5-20 BZSI-1.5-30 BZSI-1.5-40 \\
\hline $\mathrm{ZnO} / \mathrm{g}$ & 25.34 & 25.34 & 25.34 & 31.68 & 31.68 & 31.68 & 38.01 & 38.01 & 38.01 \\
$\mathrm{P} / \mathrm{g}$ & 25.34 & 25.34 & 25.34 & 31.68 & 31.68 & 31.68 & 38.01 & 38.01 & 38.01 \\
$\mathrm{NaOH} / \mathrm{mol}$ & 0.002 & 0.002 & 0.002 & 0.002 & 0.002 & 0.002 & 0.002 & 0.002 & 0.002 \\
$\mathrm{APTES} / \mathrm{wt} \%$ & 20 & 30 & 40 & 20 & 30 & 40 & 20 & 30 & 40 \\
\hline
\end{tabular}

\section{Results and discussion}

\subsection{Chemical structure analysis}

To understand the structure of the hybrid binder, some of the samples demonstrated in Table 1 were characterized by FT-IR spectra (Thermo Scientific, USA) displayed in Fig. 1.

Broad absorption peaks at around $3360 \mathrm{~cm}^{-1}$ caused by the stretching vibration of $\mathrm{Si}-\mathrm{OH}$ can be observed, which confirms that the as-prepared binder carried lots of active hydroxyls. With the increase of molar ratio of TEOS/ (MTES+DMDS), the absorption increases accordingly, which can result from that more $-\mathrm{OCH}_{2} \mathrm{CH}_{3}$ groups in

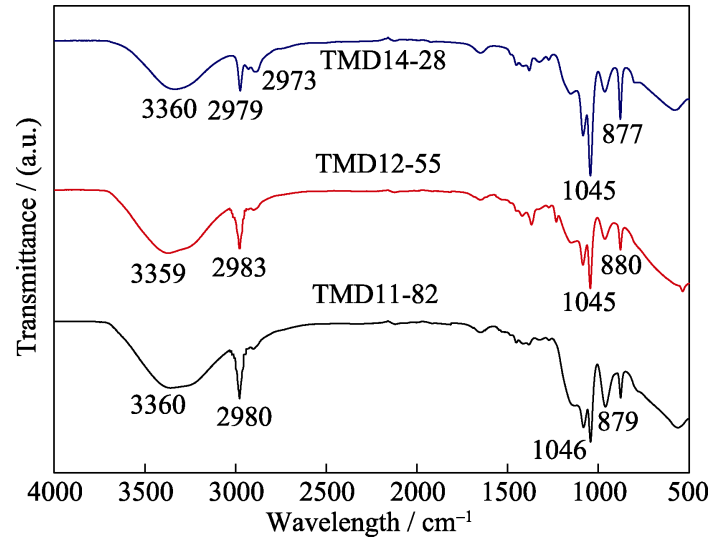

Fig. 1 FT-IR spectra of the hybrid binders with different dosages of TEOS and siloxane 
the reactants bring more active hydroxyls. No absorption peaks at around $1630 \mathrm{~cm}^{-1}$ testifies no residual water in the mixture. The sharp peaks at $1045 \mathrm{~cm}^{-1}$ are ascribed to the stretching vibrations and bending vibrations of $\mathrm{Si}-$ $\mathrm{O}-\mathrm{Si}^{[16]}$, announcing the existence of polysiloxane oligomers. Comparing sample TMD14-28 with TMD12-55, as the molar ratio of MTES/DMDS decreases, absorption peaks become sharper, proving that higher molar ratio of MTES/DMDS results in higher polymerization degree of the polysiloxane oligomers. This can be ascribed to the steric hindrance and the electronic effect ${ }^{[17]}$. Compared with TMD12-55, TMD11-82 has higher polymerization degree. This may be resulted from that more TEOS brings more active hydroxyls, which balance the steric hindrance and the electronic effect. That short sharp peaks at around $2980 \mathrm{~cm}^{-1}$ due to the asymmetrical vibration of $-\mathrm{CH}_{2}-$ in $-\mathrm{OCH}_{2} \mathrm{CH}_{3}$ group exist for all the samples suggests that the hydrolysis processes of alkoxyl groups in all the reactants are incomplete, which resulted from the reversebility of the hydrolysis process and the deficient amount of water. The absorption peaks become sharper as molar ratio of TEOS/(MTES+DMDS) increases. The small peak at $2973 \mathrm{~cm}^{-1}$ in sample TMD14-28 originates from the symmetrical stretching vibration of $\mathrm{C}-\mathrm{H}$ in $-\mathrm{OCH}_{3}$ group ${ }^{[15]}$. The same peaks, however, cannot be observed in sample TMD 12-55 and TMD11-82, indicating that DMDS in these two samples were all hydrolyzed.

\subsection{Gel Permeation Chromatography (GPC) analysis}

To have a better understanding of the polymerization degree of the hybrid binder, the molecular weight distribution of samples TMD14-28, TMD12-55 and TMD1182 were tested by GPC (Shimadzu, Japan), as shown in Fig. 2. The molar mass is at around 6000-15000 given by the peak value of molar percentage, indicating that all the samples have a relatively biggish polymerization extent.

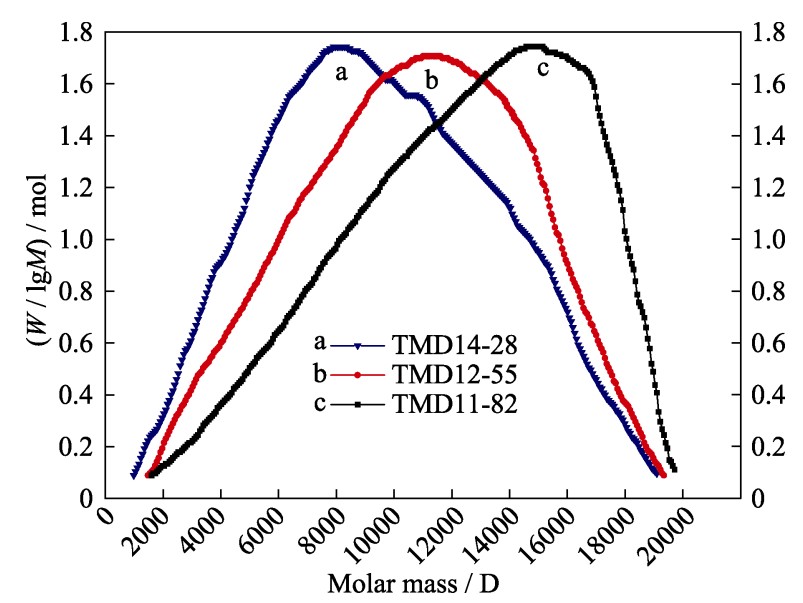

Fig. 2 GPC curves of the hybrid binder samples
This will be in favor of the next coating preparation process and properties of the final coatings, because the binder with too high polymerization degree will be difficult to be cured at room temperature ${ }^{[18]}$. The maximum molar mass increases as the molar ratios of TEOS/ (MTES+DMDS) and MTES/DMDS increase, which results from the fact that more alkoxy groups around $\mathrm{Si}$ atoms bring about more active branches in the binder structure. In conclusion, the GPC results prove that the degree of polymerization can be controlled to satisfy the requirement for the mechanical properties and curing properties of the final coatings.

\subsection{Thermogravimetric Analysis (TGA) of the coatings.}

The thermal stability of the TCCs is mainly affected by the hybrid binder. To understand the thermal behavior of the as-prepared coatings, TGA of some samples were carried out in air (Table 3 ), and TGA curves are shown in Fig. 3.

There is almost no weight loss for all the samples below $200^{\circ} \mathrm{C}$, proving that all the samples have excellent thermal stability, which indicates that the TCCs are eligible for the use of spacecraft ${ }^{[7]}$. In the temperature range of $200^{\circ} \mathrm{C}-500^{\circ} \mathrm{C}$, all the samples have a great and quick weight loss, which results from the oxidization and degradation of methyl and aminopropyl related siloxane units $^{[19-20]}$. The second weight loss stage in the curves can be ascribed to the breakage and rearrangement of

Table 3 The hybrid binder formulations of the coating samples in TGA tests

\begin{tabular}{ccccc}
\hline $\begin{array}{c}\text { Sample } \\
\text { name }\end{array}$ & TGA-1 & TGA-2 & TGA-3 & TGA-4 \\
\hline $\begin{array}{c}\text { Hybrid } \\
\text { binder } \\
\text { formulation }\end{array}$ & TMD14-28 & TMD14-55 & TMD12-28 & TMD12-55 \\
\hline
\end{tabular}

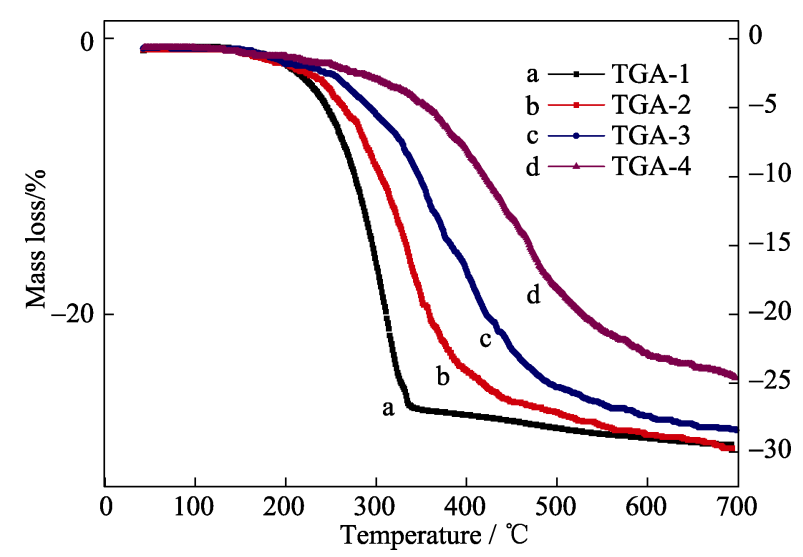

Fig. 3 TGA curves of coating samples with different binder formulations 
$\mathrm{Si}-\mathrm{O}-\mathrm{Si}$ chains in some of the oligomeric or micromolecular organosilicon molecules, generating some volatile annuluses ${ }^{[21-22]}$. As the molar ratio of TEOS/ (MTES+DMDS) increases, the onset temperature of weight loss is rising. This further proves that more TEOS or MTES can lead to more $\mathrm{Si}-\mathrm{O}-\mathrm{Si}$ chains and enhance the thermal stability of the coatings, which is consistent with the results in section 2.1.

\subsection{Solar absorption ratio $\left(\alpha_{\mathrm{S}}\right)$ and emittance $(\varepsilon)$ of as-prepared coatings}

The solar absorption $\alpha_{\mathrm{S}}$ of coatings has been tested (Perklin Elmer, USA) on the basis of the military specification of China (GJB 2502.2-2006) ${ }^{[23]}$. The emittance $\varepsilon_{\mathrm{H}}$ of coatings has also been tested (Laboratory self-made, China) by the method of Hemispherical Emittance Steady State Calorimeter according to the military specification of China (GJB 2502.3-2006) ${ }^{[24]}$.

As described in section 2.3, the as-prepared TCCs with the molar ratios of TEOS/(MTES+DMDS) $=1 / 2$ and MTES/DMDS= $1 / 1$, and the mass ratio of $\mathrm{ZnO} /$ binder= $1 / 1$ possess the best room temperature curing property and thermal stability. Four TCCs samples were chosen to test their $\alpha_{\mathrm{S}}$ and $\varepsilon_{\mathrm{H}}$, which were nominated as SE-2 to SE-5. To figure out the influence of the proportion of TEOS on their $\alpha_{\mathrm{S}}$ and $\varepsilon_{\mathrm{H}}$, the sample SE-T1 with the molar ratio of TEOS/(MTES+DMDS) $=1$ was also tested. The coatings were painted on the substrates with different thicknesses. It can be seen that all the samples have low $\alpha_{\mathrm{S}}$ and high $\varepsilon_{\mathrm{H}}$ as shown in Table 4, which indicates that the coatings possess excellent thermal controlling abilities for space assets. In addition, the $\alpha_{\mathrm{S}}$ decreases and the $\varepsilon$ increases as the coating thickness increases, which provide an effective way to further reduce the $\alpha_{\mathrm{S}} / \varepsilon_{\mathrm{H}}$ value.

To study the reflectance properties of the coatings in spectral band, the spectral reflection curves were given, as shown in Fig. 4. For SE-2 to SE-5, the solar absorption at the ultraviolet and visible wave band is relatively low, while absorption at the infrared band is high, which means the coating will have low $\varepsilon_{\mathrm{H}}$. The absorption at infrared band can be ascribed to the vibrations of organic groups in the coatings. As TEOS ratio increases, organic groups decrease, resulting in a low infrared absorption. This offers a method to further reduce coating absorptions in infrared wave band.

Table $4 \alpha_{\mathrm{S}}$ and $\varepsilon$ of TCCs with different thicknesses on the substrates

\begin{tabular}{cccccc}
\hline Samples & SE-T1 & SE-2 & SE-3 & SE-4 & SE-5 \\
\hline Thickness/ $\mu \mathrm{m}$ & 32.3 & 98.6 & 110.3 & 121.2 & 132.3 \\
$\alpha_{\mathrm{S}}$ & 0.31 & 0.30 & 0.29 & 0.25 & 0.23 \\
$\varepsilon_{\mathrm{H}}$ & 0.87 & 0.87 & 0.88 & 0.89 & 0.90 \\
\hline
\end{tabular}

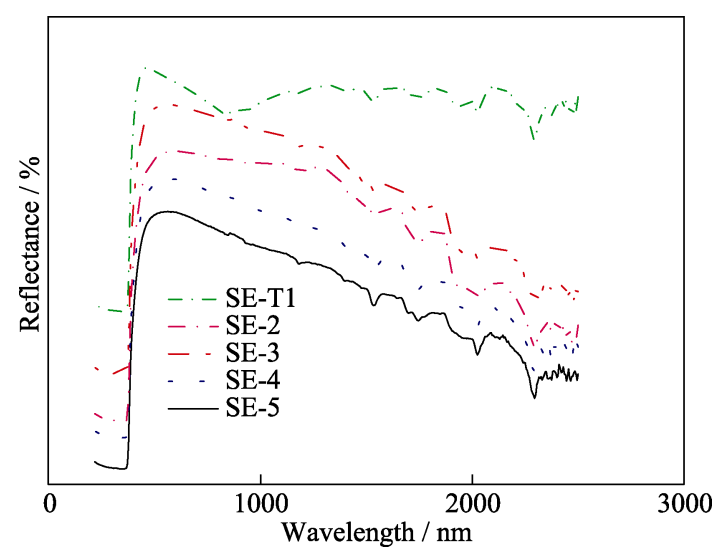

Fig. 4 Coating spectral reflection curves

\section{Conclusions}

The ZnO-based TCCs based on a novel organicinorganic hybrid binder using the as-described method have been successfully obtained. All the coatings could be curable at room temperature. More TEOS and MTES in the coatings can enhance the thermal stability of the coatings. The FT-IR spectra and GPC analysis results showed that the as-prepared hybrid binder carried lots of active hydroxyls with an appropriate polymerization degree. Besides, more TEOS and MTES would bring about more active hydroxyls, more $\mathrm{Si}-\mathrm{O}-\mathrm{Si}$ chains and higher degree of polymerization. The as-prepared coatings exhibited excellent thermal control abilities because of its low solar absorption $\alpha_{\mathrm{S}}$ and high emittance $\varepsilon_{\mathrm{H}}$. Furthermore, the $\alpha_{\mathrm{S}} / \varepsilon_{\mathrm{H}}$ value could be reduced by increasing the coating thickness, and the optical absorption of the coatings in the infrared wave band could be further reduced by increasing TEOS content.

For practical application on spacecraft, the stability properties of the coatings under spacial environment will be further studied.

\section{References:}

[1] JOHNSON JOEL, CERBUS CLIFF, HAINES AMBER, et al. Review of Improved Thermal Control Coating Development for NASA's SEE Program. 43rd AIAA Aerospace Sciences Meeting and Exhibit. Reno: Nevada, 2013: 10-13.

[2] MEMBERS OF ECSS. Space Engineering: Thermal design hand book-Part 6: Thermal Control Surfaces. Noordwijk, ESA Requirements and Standards Division, 2011: 225-251.

[3] HEYDARI V, BAHREINI Z. Synthesis of silica-supported $\mathrm{ZnO}$ pigments for thermal control coatings and analysis of their reflection model. J. Coat. Technol. Res, 2017, 7: 1-8.

[4] KIOMARSIPOUR N, RAZAVI R S, GHANI K. Improvement of spacecraft white thermal control coatings using the new synthesized Zn-MCM-41 pigment. Dyes and Pigments, 2013, 96: 403-406.

[5] XIAO H Y, LI CH D, SUN M R, et al. An analysis on optical deg- 
radation of $\mathrm{ZnO} /$ silicone white paint under proton exposure. $\mathrm{Nucl}$. Instr. and Meth. in Phys. Res, 2008, 266(B): 86-92.

[6] SHRESTHA S, PINO CBD, MALAYOGLU U. Inorganic white thermal-control coatings for extreme space environments. Journal of Spacecraft and Rockets, 2016, 53(6): 1-7.

[7] LEI H, LU W, ZENG Y B, et al. Space Environmental and Technical Performances of Organic Silicone Antistatic White Thermal Control Coating. Protection of Materials and Structures from the Space Environment, Astrophysics and Space Science Proceedings 47, 2017: 43-51.

[8] CHENG X W, LIANG CH X, GUAN J P, et al. Flame retardant and hydrophobic properties of novel Sol-Gel derived phytic acid/silica hybrid organic-inorganic coatings for silk fabric. Applied Surface Science, 2017, 8: 1-38.

[9] DHAWADE P, JAGTAP R. Comparative study of physical and thermal properties of chitosan-silica hybrid coatings prepared by Sol-Gel method. Der Chemica Sinica, 2012, 3(3): 589-601.

[10] FIGUEIRA R B, SILVA C J R. Organic-inorganic hybrid Sol-Gel coatings for metal corrosion protection: a review of recent progress. Journal of Coatings Technology and Research, 2015, 12(1): 1-35.

[11] OMAR S, PELLICE S, BALLARRE J, et al. Hybrid organicinorganic silica-based coatings deposited by spray technique. Procedia Materials Science, 2015, 9: 469-476.

[12] DEMIRER H, KARTAL İ, ÇAKIR M. Improvement of the surface properties of polystyrene sheets via UV curable organic-inorganic hybrid coatings. Acta Physica Polonica, 2017, 131(3): 555-559.

[13] JANKAUSKAITE V, LAZAUSKAS A, GRIŠKONIS E, et al. UV-curable aliphatic silicone acrylate organic-inorganic hybrid coatings with antibacterial activity. Molecules, 2017, 22(6): 964-977.

[14] PLINIO INNOCENZI, GIOVANNA BRUSATIN, SILVIA LICOCCIA, et al. Controlling the thermal polymerization process of hybrid organic-inorganic films synthesized from 3-aminopropyltriethoxysilane. Chem. Mater., 2003, 15(25): 4790-4797.
[15] CHEN X B, ZHOU S X, YOU B, et al. Ambient-curable polysiloxane coatings: structure and mechanical properties. Journal of Sol-Gel Science and Technology, 2011, 58(2): 490-500.

[16] LI Y S, WANG YU, TRAN T, et al. Vibrational spectroscopic studies of (3-mercaptopropyl)trimethoxylsilane Sol-Gel and its coating. Spectrochim Acta Part A, 2005, 6(13/14): 3032-3037.

[17] LI Y S, WANG Y, CEESAY S. Vibrational spectra of phenyltrithoxysilane, ohenyltrimethoxysilane and their Sol-Gels. Spectrochim Acta Part A, 2009, 70: 1819-1824.

[18] ZHU D Q, OOIJ W V. Structural characterization of bistriethoxysilyipropyl tetrasulfide and bis-trimethoxysilylpropyl amine silanes by Fourier-transform infrared spectroscopy and electrochemical impedance spectroscopy. Journal of Adhesion Science and Technology, 2002, 16(9): 1235-1260.

[19] LI Y S, WANG Y, TUAN T, et al. Studies of (3-mercaptopropyl) trimethoxylsilane and bis(trimethoxysilyl)ethane Sol-Gel coating on copper and aluminum. Spectrochim, Acta Part A, 2009, 73(5): 922-928.

[20] CHEN X B, ZHOU S X, YOU B, et al. Mechanical properties and thermal stability of ambient-cured thick polysiloxane coatings prepared by a Sol-Gel process of organoalkoxysilanes. Progress in Organic Coatings, 2012, 74(3): 540-548.

[21] JONES R G, WATARU ANDO, CHOJNOWSKI J, et al. Siliconcontaining Polimers: The Science and Technology of Their Synthesis and Applications Beijing: Chemical Industry Press, 2008: 153-157.

[22] ZHANG J, FENG S Y, MA Q Y. Kinetics of the thermal degradation and thermal stability of conductive silicone rubber filled with conductive carbon black. Journal of Applied Polymer Science, 2003, 89(6): 1548-1554.

[23] GJB 2502.2-2006. The Method for Thermal Control Coatings of Spacecraft, Part 2: Measurement of Solar Absorptance.

[24] GJB 2502.3-2006. The Method for Thermal Control Coatings of Spacecraft, Part 3: Measurement of Emissivity.

\section{有机/无机杂化室温固化热控涂层的制备}

$$
\text { 刘 }{ }^{1,2,3} \text {, 于 } \text { 洋 }^{1} \text {, 米 }{ }^{1} \text {, 于 云 }{ }^{1} \text {, 宋力昕 }{ }^{1}
$$

(1. 中国科学院 上海硅酸盐研究所, 中国科学院无机特种涂层重点实验室, 上海 200050; 2 . 中国科学院大学, 北 京 100049; 3. 上海科技大学 物质科学与技术学院, 上海 201210)

摘 要: 以正硅酸乙酯(TEOS)与硅氧烷共水解缩聚反应制备得到粘结剂, 然后与作为固化催化剂的 3-氨基丙基三乙 氧基硅烷(APTES)和作为光学颜料的 ZnO 粉末混合, 制备了一系列有机-无机杂化热控涂层(TCCS)。所制备的热控 涂层可以在室温下自然固化, 且具有较低的太阳吸收比 $\alpha_{\mathrm{S}}$ 和较高的发射率 $\varepsilon_{\mathrm{H}}$ 。红外光谱(FT-IR)和凝胶色谱(GPC) 分析结果表明, 所制备的混合粘结剂含有大量的活性羟基, 聚合度适中。热重分析(TGA)表明, 所制备的热控涂层 在 $200^{\circ} \mathrm{C}$ 以下具有良好的热稳定性。通过增加涂层厚度可以降低 $\alpha_{\mathrm{S}} / \varepsilon_{\mathrm{H}}$ 值, 通过提高 TEOS 含量, 可以降低涂层在 红外波段的光学吸收。这为获得具有低 $\alpha_{\mathrm{S}} / \varepsilon_{\mathrm{H}}$ 值的室温固化 TCCS 提供了有效途径。

关 键 词: 室温固化; 热控涂层; 热稳定性; 低 $\alpha_{\mathrm{S}} / \varepsilon_{\mathrm{H}}$ 值

中图分类号: TQ174 文献标识码: A 